\title{
Mulheres em situação de rua: memórias, cotidiano e acesso às políticas públicas
}

\author{
Scarleth Nardes' (i0) 0000-0003-2323-4419 \\ Carmem Regina Giongo' id 0000-0001-7335-851 1
}

'Universidade Feevale, Novo Hamburgo, RS, Brasil.93525-075 - proppex@feevale.br

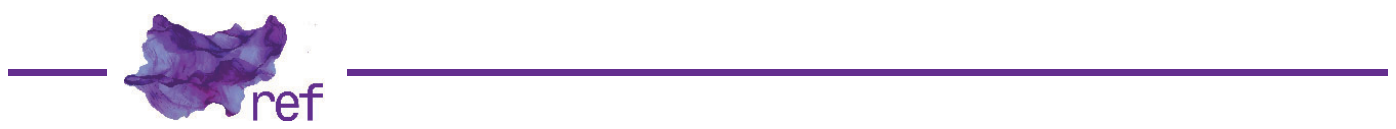

\begin{abstract}
Resumo: Neste estudo, objetiva-se analisar as vivências de mulheres em situação de rua da região do Vale do Sinos, no Rio Grande do Sul, resgatando suas memórias, cotidiano e acesso às políticas públicas. Trata-se de uma pesquisa de caráter exploratório-descritivo e de metodologia qualitativa. Foram realizadas observações participantes associadas à aplicação de um questionário sociodemográfico e de uma entrevista de história de vida. Participaram deste estudo 10 mulheres em situação de rua, com idade entre 20 e 61 anos. A análise do material coletado se deu por meio da análise de conteúdo. Os resultados apontaram para a necessidade de políticas públicas voltadas para as mulheres em situação de rua, considerando seus modos de vida e vivências na rua.
\end{abstract}

Palavras-chave: mulheres; população em situação de rua; políticas públicas; saúde pública.

Homeless Women: Memories, Daily Life and Access to the Public Policies

Abstract: This study aims to analyze experiences of homeless women in the region of Vale do Sinos, in Rio Grande do Sul, retrieving their memories, daily lives and access to the public policies. It is an exploratory and descriptive research which used a qualitative methodology. Participant observationswere conducted and related tothe use of a sociodemographic questionnaire and a life history interview. Ten homeless women, aged between 20 and 61, participated in this study. The analysis of the material collected was made through content analysis. The results pointed out the need for public policies aimed at homeless women, which consider the way they live and their experiences as homeless people.

Keywords: Women; Homeless persons; Public policies; Public health.

\section{Introdução}

O cenário da População em Situação de Rua (PSR) apresenta-se como um fenômeno diversificado, que aflige diferentes grupos de pessoas de várias maneiras. Trata-se da manifestação da incapacidade dos governos de enfrentar as crescentes desigualdades de renda, riqueza e acesso a terra e à propriedade, bem como à incapacidade de responder efetivamente aos problemas da urbanização e migração. Neste contexto, a moradia é tratada como uma mercadoria e não como um direito humano (HUMAN RIGHTS COUNCIL, 2015).

A expressão 'situação de rua' retrata tanto a carência de moradia quanto também descreve um grupo social. A relação restrita entre a negação de direitos e uma identidade social define a ausência de moradia da exiguidade de outros direitos socioeconômicos. Neste contexto, é comum que as pessoas em situação de rua vivenciem estigmatização, exclusão social e criminalização (HUMAN RIGHTS COUNCIL, 2015).

A diversidade dos modos de classificação categóricos - tais como clochard, homeless, sem-abrigo, sem-teto, sem-domicílio fixo, morador de rua, pessoa em situação de rua - possibilita a compreensão da relação que se estabelece entre a definição de elementos populacionais e as determinadas práticas de sujeitos e um conjunto heterogêneo de intervenções. Como exemplo, nos países anglo-saxões e franceses, a definição origina-se da não moradia: são os homeless e os sem-domicílio fixo. Já na tradição brasileira, atribui-se uma designação relacionada à vida 
na rua, com as noções de morador de rua e população em situação de rua (PSR) (Viviane de Souza PEREIRA, 2007; Patrice SCHUCH et al., 2008). Considerando a multiplicidade de condições pessoais, a diversidade de soluções dadas à subsistência e à moradia, torna-se difícil definir a população de rua, tendo em vista os fatores que dificultam a formulação de conceitos livres de ambiguidades (Anderson da Silva ROSA; Maria Gabriela Secco CAVICCHIOLI; Ana Cristina Passarella BRÊTAS, 2005).

Ainda segundo Rosa, Cavicchioli e Brêtas (2005), identificam-se situações diferentes em relação à permanência na rua: há aqueles que podem ficar na rua circunstancialmente; estar na rua recentemente ou ser da rua permanentemente. O tempo vivido como moradores de rua é um componente complicador nesse processo, pois quanto maiores os desvios de tempo, circunstancial ou recentemente nas ruas, maiores serão as probabilidades de se tornarem perduráveis como seres da rua.

Referente a estimativas estatísticas, a PSR não participa das pesquisas do Instituto Brasileiro de Geografia e Estatística (IBGE), visto que a coleta de dados para os censos é sobretudo de base domiciliar e a maior parte dessa população não possui residência (ROSA; CAVICCHIOLl; BRÊTAS, 2005). Apesar disso, são milhares de pessoas e famílias que vivem na rua e, quando organizadas, optam por serem chamadas de 'pessoas em situação de rua', objetivando configurar o princípio da transitoriedade desse processo de completa exclusão social, mesmo que reconheçam, por vezes, que sair da rua não é tão fácil (Maria Magalhães AGUIAR; Jorge Alberto Bernstein IRIART, 2012).

Um estudo realizado pelo Instituto de Pesquisa Econômica Aplicada (IPEA) em 2016 identificou 101.854 pessoas em situação de rua no Brasil, sendo a maior concentração em municípios de grande porte ou capitais (Marco Antonio Carvalho NATALINO, 2016). Já na capital do Rio Grande do Sul, Porto Alegre, um estudo censitário apontou para a existência de 2.115 pessoas adultas em situação de rua. Deste total, 85,5\% eram homens, 59, 1 \% eram naturais de Porto Alegre ou da região metropolitana e 61,4\% possuíam mais de 35 anos (PORTO ALEGRE, 2016).

No que se refere às mulheres em situação de rua, segundo o Ministério do Desenvolvimento Social e Combate à Fome, no Brasil, são encontrados poucos estudos sobre a temática, mostrando a incipiência de investigações sobre as peculiaridades dessa população. Estima-se que a porcentagem de mulheres em situação de rua seja de 18\% no cenário nacional, muito inferior aos homens (BRASIL, 2008).

Do ponto de vista internacional, uma pesquisa realizada na cidade de Nova York que envolveu 141 mulheres em situação de rua apontou para índices significativos de violência física e estupro. Das 141 entrevistadas, 21 foram estupradas, 42 relataram terem sido estupradas e agredidas e 62 foram agredidas, sem ocorrência de abuso sexual. Os pesquisadores concluíram que a maior parte das necessidades de assistência à saúde era consequência desta realidade, como o cuidado com traumas físicos ou problemas de saúde mental relacionados (Ann D'ERCOLE; Elmer STRUENING, 1990).

Em outro levantamento realizado em Los Angeles, no qual foram entrevistadas 974 mulheres em situação de rua, 13\% comunicaram terem sofrido estupro no último ano. Essas mulheres manifestaram piores danos no estado geral da saúde por terem vivenciado esse tipo de violência: sintomas ginecológicos aumentados, uso abusivo de álcool e outras drogas e aumento significativo dos casos de depressão (Suzanne L. WENZEL; Barbara D. LEAKE; Lilian GELBERG, 2000).

No que se refere ao contexto brasileiro, as informações sobre a violência sofrida por mulheres da população geral não são notificadas, visto que a maior parte possui receio em denunciar o agressor por desacreditar na segurança que o Estado deveria lhes conceder. Este processo não é diferente com as mulheres em situação de rua, possivelmente de maneira mais grave, embora ainda não haja exatidão nessa afirmação. Rosa (2012) destaca, em seu estudo, que, para as mulheres, viver nas ruas faz com que busquem constituir relações que proporcionem a viabilidade cotidiana da sua vida, visto que, sozinhas, se apresentam mais vulneráveis às violências. Izalene Tiene (2004) corrobora esse fato, ressaltando que as mulheres em situação de rua não vivem desacompanhadas e buscam conviver em grupos para se protegerem. Em muitos momentos, acabam procurando parceiros para se sentirem seguras e submetem-se sexualmente para garantir a seguridade. Nas palavras de Tiene (2004, p. 156): "as mulheres mantêm a submissão sexual em troca de proteção e pagam muito caro por isso. Seus corpos revelam traços de 'utilidade obediência'",

Um estudo realizado em São Paulo por Luciana Rossani Tiradentes e Rosa Aurea Quintella Fernandes (2008) mostrou que as participantes da pesquisa viviam na rua há cinco anos em média, apontando para a ineficácia das políticas públicas e dos programas sociais neste âmbito. Rubens de Camargo Ferreira Adorno, Augusta Thereza Alvarenga e Maria da Penha Vasconcellos (2004) afirmam que os programas sociais desenvolvidos neste contexto trazem a marca ideológica do descarte social de uma população que é tratada como excluída. São programas marcados pela institucionalização de práticas que visam à retirada destas pessoas das ruas, oferecendo, entretanto, poucas possibilidades de uma reestruturação para suas vidas, segundo os autores. 
As mulheres e adolescentes em situação de rua, via de regra, encontram inúmeras barreiras para acessar ações e serviços públicos de saúde. Isso decorre de várias ausências, tais como de informação, de documentação, de endereço convencional, entre outros. No âmbito do SUS, gestores e profissionais de saúde precisam estar atentos a essas especificidades, atuando na eliminação dessas barreiras e garantindo o acesso universal e igualitário às ações e aos serviços de saúde (BRASIL, 2015).

Diante destas inúmeras problematizações e buscando ampliar o olhar sobre esta temática, o objetivo deste estudo é analisar as vivências de mulheres em situação de rua da região do Vale do Sinos, no Rio Grande do Sul, resgatando suas memórias, cotidiano e acesso às políticas públicas.

\section{Percurso metodológico}

Este estudo possui um delineamento exploratório-descritivo, de método qualitativo. A pesquisa exploratória tem como finalidade possibilitar a ampliação de informações sobre o assunto que será investigado, além de facilitar a delimitação do tema da pesquisa (Cleber Cristiano PRODANOV; Ernani Cesar de FREITAS, 2013).

Os instrumentos utilizados para a pesquisa foram um questionário sociodemográfico, com o objetivo de caracterizar as participantes, uma entrevista conduzida a partir do método de história de vida e observações participantes com uso de diário de campo. No que se refere ao método de história de vida, trata-se de uma técnica precisamente histórica, marcada pela temporalidade contida no relato individual, que remete ao tempo histórico. É dinâmica, pois compreende os processos de mudanças de estruturas de vínculos sociais e, por último, dialética, devido a teoria e prática estarem constantemente sendo confrontadas no decorrer da investigação (Lucila Reis BRIOSCHI; Maria Helena B. TRIGO, 1987). Essa técnica possibilita que as mulheres em situação de rua possam descrever, relatar e contar à sua maneira suas vivências, sua história de vida, "e assim nos fazer compreender as dinâmicas das relações que se estabelecem ao longo de sua existência" (Thelma SPINDOLA; Rosângela da Silva SANTOS, 2003, p. 121).

As entrevistas realizadas nesta pesquisa ocorreram individualmente. Em primeiro lugar, realizou-se o contato com os Centros de Referências Especializados para População em Situação de Rua (Centros POP), da cidade de Novo Hamburgo e São Leopoldo, no estado do Rio Grande do Sul. Posteriormente, os trabalhadores dos locais indicaram as entrevistadas para a pesquisadora, que realizou a coleta de dados nos próprios serviços. Após a coleta dos dados, as entrevistas foram transcritas na íntegra para a análise de dados.

Participaram da pesquisa 10 mulheres em situação de rua, com idades entre 20 e 61 anos e tempo de permanência na rua que variou de 15 dias a 14 anos. Quanto ao estado civil, todas se declararam solteiras, porém duas afirmaram possuir um parceiro no momento da pesquisa. Em relação à escolaridade das entrevistadas, três possuíam ensino fundamental completo, três ensino fundamental incompleto, uma segundo grau completo e três segundo grau incompleto. Quanto ao número de filhos, três mulheres possuíam um filho, duas mulheres não possuíam filhos e as demais possuíam de três a 10 filhos. Quanto à atividade profissional, seis estavam desempregadas, três trabalhavam com reciclagem de materiais e uma era pensionista. Em relação aos vínculos familiares, sete mulheres possuíam vínculo familiar e três não possuíam. Quanto aos serviços acessados pelas mulheres, 10 frequentavam o Centro POP, cinco frequentavam albergues, uma frequentava o Centro de Atenção Psicossocial (CAPS), uma o Centro de Referência de Assistência Social (CRAS) e uma estava vinculada a uma casa de passagem.

Destaca-se, neste levantamento, o alto índice de vivências de violência na rua: das 10 entrevistadas, seis declararam ter sofrido abuso sexual, duas sofreram violência psicológica e duas alegaram não terem sofrido nenhum tipo de violência. Em relação ao uso de substâncias psicoativas, quatro não faziam uso e as demais utilizavam maconha, crack, álcool, cocaína e cigarro.

Os dados coletados nessa pesquisa por meio da observação participante, do questionário sociodemográfico e das entrevistas de história de vida foram submetidos à análise de conteúdo apresentado por Laurence Bardin (2009). Sobre os aspectos éticos, este projeto de pesquisa foi submetido ao Conselho de Ética em Pesquisa da Universidade Feevale e aprovado no dia 18 de dezembro de 2017, sob parecer número 2.444.183.

\section{Análise e discussão dos resultados \\ Os caminhos da rua: memórias, cotidiano e sofrimento}

Caminhos cruzados, alados, falados / Tropeços, regados a fatos calados / Da rua que traz / Da rua que leva / Memórias vividas, geradas, passadas... (Scarleth Nardes)

Este eixo temático, intitulado "Os caminhos da rua: memórias, cotidiano e sofrimento", foi composto a partir de quatro temáticas principais, quais sejam: as relações que as entrevistadas 
estabelecem na situação de rua, a vulnerabilidade, a identidade das mulheres e o sofrimento social. Finalmente, serão abordadas as inter-relações entre estas vivências e as demandas de saúde das participantes.

Na rua são construídas relações cotidianas que se estabelecem a partir das identificações dos sujeitos que ali vivem. Em muitos relatos, aqui apresentados com nomes fictícios, identificaramse as relações de cuidado e de confiança entre as pessoas que vivem em situação de rua, dentre eles:

[... que nem teve uma época que eu parei de usar droga que eu ajudava todos esses moradores de rua, fazendo comida, dando um colchão para eles dormir, dando uma coberta para eles se cobrir, hoje eu tô na rua que nem eles, mas eles sempre me apoiaram eu nunca vou deixar de apoiar, nem se um dia eu tiver bem de vida, sabe [...] (DIANA, informação verbal, 2017).

Nas palavras de Roberta (informação verbal, 2017): Eu uso com meus amigos aqui da outra avenida, porque a gente já se conhece faz anos, sabe, porque tu tem a confiança, tu vai usar, eles vão ficar do meu lado, ou vamos beber uma cachaça, vamos ficar todo mundo de boa.

Além disso, nas análises das entrevistas, pode-se constatar que muitos dos vínculos são estabelecidos com os profissionais e usuários dos serviços públicos e filantrópicos acessados pela população em situação de rua, onde essas mulheres se sentem acolhidas. Em um dos discursos, pode-se observar:

[...] por isso que eu gosto de ir pra casa de apoio, eu gosto de ir pro albergue que eu tenho minhas amizades. No trecho que eu digo, os trecheiros, que eu vou encontro aqui, encontro lá em Floripa, encontro em Porto Alegre, é aquela alegria, todo mundo se dá bem, entendeu? Aí eu não tô sozinha (CIGANA, informação verbal, 2017).

Os vínculos familiares anteriores ao ingresso da rua também são buscados, apesar de muitas vezes terem sido o motivo de essas pessoas adentrarem na rua ou até mesmo de permanecerem nela. O limite é dado em algumas circunstâncias, devido à realidade vulnerável em que se encontram. Uma das entrevistadas relata: Eu fumo minha maconha, então eu disse: a mãe vai cortar a tua visita porque os caras já estavam dizendo 'a tua filha é muito linda, quer ser minha sogra?'. Aquela coisa toda, sabe? Aí a guria vai acabar se estragando (DIANA, informação verbal, 2017).

As relações são frágeis e a maneira como as redes existem concebe maior ou menor grau de suporte social. Os processos de vulnerabilidade social são produzidos por meio de relações de baixa qualidade, que têm como características a fragilidade e fugacidade, carência de suporte estável, além da caracterização do cotidiano na rua por convívios superficiais ou por processos de ruptura dos vínculos profundos. São as redes de suporte que proporcionam a ajuda necessária para obter e sustentar o equilíbrio dinâmico entre a vulnerabilidade e integridade (Luana Padilha ANDRADE; Samira Lima da COSTA; Fernanda Cristina MARQUETTI, 2014).

Quanto à questão da vulnerabilidade, a população em situação de rua vive-a constantemente. São vulneráveis por não terem emprego estável ou dinheiro, não possuírem documentação e casa. Enfim, são vulneráveis por não terem a possibilidade de acesso à educação e por depararem-se com dificuldades para obter até mesmo cuidados de saúde. Esse contexto intensifica episódios de medo, fome e violência que essas pessoas vivenciam constantemente no seu cotidiano (Marília SOTERO, 2011).

Nas análises das entrevistas realizadas fica demarcada a violência vivenciada por cada uma dessas mulheres, além dos desafios enfrentados por elas no ambiente da rua. Não obstante, essa temática remete à reflexão relacionada ao preconceito que mulheres sofrem por estarem em situação de rua. Pode-se observar isso nos discursos a seguir, marcados pelos sentimentos de rejeição e repúdio: [...] eu sou moradora de rua... Me chamam de vagabunda, eu sei que não sou vagabunda, sei que não faço programa, sei que não roubo mais nada de ninguém, trabalho honestamente, e não quero que muitos amigos meus sejam comparados aos outros (DIANA, informação verbal, 2017); A gente ouve muito... Ah, além de ser puto anda na rua, vários tipos de ofensa... A mulher que tá ali dormindo, quando vê tem um homem passando a mão em ti (ROBERTA, informação verbal, 2017); [...] daí eu tô no meio dos guris, sou a única mulher que fica no meio deles, sou a única casada, daí eles comentam assim: bá, sabe a fulana, ontem eu comi ela, eu fiz isso com ela, sabe? Falando aquelas coisas nojentas... (VALQUíRIA, informação verbal, 2017).

Por vezes, as situações de vulnerabilidade fazem com que as mulheres se questionem quanto ao seu próprio valor. Há muito sofrimento manifestado em suas falas e interrogações sobre os motivos que as levaram para a rua e as oportunidades que lhes são ou não ofertadas. Uma entrevistada indaga:

Eu tive que escutar, eu tive que aguentar, eu me pergunto assim será que tudo isso foi necessário pra mim aprender alguma coisa? Será que isso daí foi meu aprendizado, uma lição de vida que eu tive que ter? Me refiro ao ser humano, sabe? Porque eu acho o seguinte: o ser ele falha, mas ele também tem coisas boas, assim como tu vê uma raiz de uma árvore podre e uma raiz 
de uma árvore nova, né, tu vai dar mais valor pra quem? Tu vai dar mais valor pra qual raiz? Tu vai cuidar da podre que tá apodrecendo ou tu vai cuidar da nova que pode dar mais galhos, né? E dos galhos se ela for frutífera, ela vai vir com mais frutos (CORA, informação verbal, 2017).

Dessa forma, percebe-se que os caminhos percorridos na rua são repletos de desafios. Viver e sobreviver são vitórias tanto pessoais como coletivas, visto que assegurar sua própria vida é vantagem com relação à realidade imprevisível do cotidiano nas ruas. Salienta-se a violência de gênero e a agressividade na rotina de toda a população em situação de rua, tornando-se evidente a vulnerabilidade corporal neste espaço.

É nesse contexto que as mulheres em situação de rua vão construindo seus caminhos e suas identidades. É também nessa rede de relações que se estabelece uma memória social. Segundo Lima da Costa (2008), a memória social se configura por construções sociais em contínua transformação, buscando, simultaneamente, conservar algo do passado no presente. 0 modo de agir e pensar do indivíduo é reflexo dessas experiências. Nessa perspectiva, sua maneira de enfrentar a vida, o mundo, sua existência individual e tudo que a compreende também se transformará.

No que se refere à identidade das mulheres nas relações que se estabelecem, as análises das entrevistas retratam situações em que as entrevistadas se descrevem tanto como mulheres em situação de rua, como também sujeitas que exercem o papel de mãe, irmã e filha diante de suas vivências do passado e atuais. Quanto às relações familiares estabelecidas com suas próprias mães, destaca-se que algumas mulheres possuem vínculo materno e que, muitas vezes, são suas mães que acabam cuidando dos seus filhos gerados na rua.

Outro aspecto observado foi a relação fraternal entre elas e suas irmãs e irmãos, visto que muitos dos vínculos foram rompidos até mesmo antes da ida para as ruas. Em outros casos, verifica-se que permanece uma relação dominante, na qual se estabelece um controle sobre a vida das mulheres ou, ao contrário, uma relação afetuosa. Quanto ao relacionamento com os filhos, observa-se que os vínculos são diferenciados: em alguns casos, há a perda total de vínculo, por motivos relacionados às drogas e/ou à doença mental; e em outros casos, essas relações são próximas. Uma entrevistada menciona: Corta o coração de um filho saber que tua mãe que te deu estudo, te deu amor, te deu carinho, nunca deixou faltar nada, daí de uma hora para outra se transformar nessa pessoa para eles... (VALQUÍRIA, informação verbal, 2017).

Foi identificada que uma expectativa das mulheres é a reaproximação da família. Isso denota o valor que a presença da família representa na vida das entrevistadas. Segundo uma pesquisa realizada no Paraná, ainda que esteja vinculada como responsável pela busca pela situação de viver na rua, na maioria dos casos, as participantes demonstraram desejo de formar ou reconstruir uma nova família. Isso demonstra que o ser humano rompe vínculos afetivos, mas permanece a sonhar, a reconfigurar suas relações, a restaurar as pregressas e traçar um novo viver (Joisy Aparecida MARCHI; Lígia CARREIRA; Maria Aparecida SALCl, 2013).

Ainda assim, o sofrimento social está presente na vivência das mulheres neste contexto, visto que estão numa posição de 'indivíduos por falta'. A escassa visibilidade social faz com que vivenciem e experienciem diretamente a humilhação, falta de reconhecimento e vergonha, que deixam marcas psíquicas (Teresa Cristina CARRETEIRO, 2003). Além disso, as mulheres em situação de rua vivem em circunstâncias extremas de exclusão social. Inseridas num contexto de abandono e miséria, habitam praças públicas, terminais de ônibus, calçadas, viadutos e espaços públicos. Esses cenários de desemparo configuram visivelmente a alta vulnerabilidade psicossocial (Carlos Eduardo ESMERALDO FILHO, 2006).

No que se refere aos aspectos da saúde, diversos relatos foram trazidos no decorrer das entrevistas. As mulheres relacionam o estar 'doente', por exemplo, à incapacidade de locomoverse. Devido aos sintomas da AIDS, uma usuária relata sentir-se impossibilitada para buscar medicamentos, visto que não possui a documentação necessária para realizar a solicitação. Esse aspecto apresenta diversas questões reveladoras sobre a estruturação, a dinâmica do atendimento, as atitudes dos profissionais de saúde e, de certo modo, a reprodução da exclusão social na atenção à saúde dessa população.

Outra questão levantada é a higiene pessoal e os desafios que as mulheres em situação de rua encontram pela falta de privacidade, sendo notória a perda da autoestima. Segundo Brêtas, Rosa e Cavicchioli (2006), a situação de rua não assegura condições básicas de vida e, quando vinculada ao sofrimento cotidiano e à falta de possibilidades de melhorias, essa circunstância pode desencadear a perda da autoestima e, por conseguinte, a ausência de preocupação com o autocuidado. Uma das entrevistadas salienta: [...] a mulher tipo gosta, pelo menos eu gosto de tomar banho, é mais difícil porque homem aguenta, mulher já não aguenta ficar sem tomar banho, sem tipo, fazer sua higiene, necessidades dela, pro homem vai pra um canto, mija (ROBERTA, informação verbal, 2017).

No que se refere à saúde mental, foram observadas importantes demandas, inclusive a dificuldade de acesso aos serviços de saúde que proporcionam os tratamentos. Uma das 
entrevistadas relata a banalização do seu adoecimento: [...] elas não entendem o meu lado, por causa da minha depressão, que houve uma tragédia na minha vida, eu fiquei com essa depressão, não consigo desligar, porque eu perdi um filho, foi um assassinato (CIGANA, informação verbal, 2017).

Outro fator que contribui para o adoecimento é o uso de substâncias psicoativas, como o álcool e outras drogas:

Se eu tivesse uma casa hoje, crack eu não usaria mais, tem muitos que já tiveram essa oportunidade, até eu já tive essa oportunidade e não consegui cumprir, olha, eu já botei muito a minha vida fora, eu já tô com quase 40 anos nas costas, vou morrer fumando crack e não vou ter minha casa mais (DIANA, informação verbal, 2017).

Nós ia pra boca, sabe? Pra usar droga passava 24 horas às vezes, a gente ficava cinco ou seis dias sem dormir só usando droga... Uma vez a gente ficou até 12 dias sem dormir, imagina... Só usando droga... E caminhando, sabe, sem tomar um banho (VALQUíRIA, informação verbal, 2017).

O debate sobre drogas contribui para criminalizar ainda mais essa população, que já sofre com o processo de segregação social. Como relembra Carreteiro (2003), as lógicas de invalidação e de depreciação acontecem, na maioria das vezes, em cenas públicas. Os sujeitos sentem-se diminuídos, desvalorizados e dificilmente partilham esses sentimentos. Sob a perspectiva dos sujeitos, a expressão dos sentimentos sofre uma autocensura, já que a sociedade proporciona pouco suporte para facilitar sua expressão. Os afetos, resultantes do sistema de exclusão, são banidos e passam por um processo que objetiva anulá-los e apagá-los, tornando-os impercebíveis. A esse processo de silenciamento dos afetos, do qual as instituições e os indivíduos ímpares e coletivos participam, designou-se, aqui, lógica da invisibilidade do sofrimento. De fato, muitos desafios são encontrados na forma de desenvolver ações que possibilitem a promoção de saúde à população em situação de rua. Carmen Lúcia Albuquerque Santana e Rosa (2016, p. 51) citam que a complexidade dos hábitos de vida na rua dificulta a superação desses desafios, pois seria necessário:

[...] ter um sono reparador; boa alimentação; boa higiene; praticar atividade física regularmente (que é diferente de ter que caminhar muito por obrigação ou ter um trabalho que exija fisicamente); poder fazer atividades que dão prazer; ter momentos de tranquilidade; desenvolver laços afetivos aumentando sua rede de suporte social.

Além disso, principalmente, o desafio está centrado na concepção, construção e funcionamento das políticas públicas que nem sempre consideram as particularidades de ser mulher nas ruas.

\section{O lugar das mulheres nas políticas públicas para a população em situação de rua}

População que aqui se encontra / No lugar que não me encontra / Das políticas, do público, da rua / Do encontro e desencontro / Do que é público (Scarleth Nardes).

A Política Nacional para Inclusão Social da População em situação de rua (BRASIL, 2008) é resultado de uma interdisciplinaridade de grupos de trabalho interministerial, respaldada pelo Decreto s/n, de 25 de outubro de 2008, constituído pelo Ministério do Desenvolvimento e Combate à Fome, Ministério da Educação, Ministério das Cidades, Ministério do Trabalho e Emprego, Ministério da Justiça, Ministério Especial de Direitos Humanos e Defensoria Pública da União, além do Movimento Nacional de População de Rua (MNPR), da Pastoral do Povo de Rua e do Colegiado Nacional de Gestores Municipais da Assistência Social (CONGEMAS) (BRASIL, 2008). No entanto, esta política ainda não está implementada e sendo executada em todos os Estados. Dessa maneira, são inexistentes políticas públicas destinadas às mulheres em situação de rua, considerando que, infelizmente, as outras políticas que incluem o sexo feminino não envolvem as mulheres dentro dessa situação, colocando-as numa posição de excluídas até mesmo das políticas de inclusão (CONSELHO REGIONAL DE PSICOLOGIA 2a REGIÃO, 2015).

Em referência às políticas públicas que prestam atendimento especializado às pessoas em situação de rua, em Novo Hamburgo, São Leopoldo e Porto Alegre, os serviços mais acessados pelas 10 mulheres em situação de rua entrevistadas foram os Centros de Referência Especializados para População em Situação de Rua (Centro POP), abrigos, albergues, Centros de Atenção Psicossocial (CAPS), Centro de Referência de Assistência Social (CRAS) e algumas já frequentaram comunidades terapêuticas. O Centro POP e os albergues foram os mais citados pelas entrevistadas.

Constata-se, por meio dos relatos, que o Centro POP é um serviço de referência para esta população, local no qual podem tomar banho, se alimentar, solicitar ajuda com a documentação, bem como ter conhecimento de vagas de emprego, além de este se tornar um ambiente de socialização. Quando questionadas sobre quais as melhorias que poderiam ser realizadas nos 
serviços para melhor atender às necessidades da população em situação de rua, as entrevistadas mostraram-se críticas.

Especificamente quanto aos Centros POP, as mulheres mencionaram gostar dos atendimentos oferecidos, porém argumentam que o local não consegue distribuir vale-transporte para todos os moradores, devido à grande demanda, e que essa falta faz com que muitos não possam transitar por outros municípios. Quanto ao atendimento mais específico para as demandas das mulheres, uma das solicitações que abrangem as necessidades refere-se aos serviços de saúde. Segundo uma entrevistada, faz-se imprescindível ter uma psicóloga do sexo feminino escutando suas reivindicações: Aqui tem um psicólogo homem, mas não é a mesma coisa, porque tem coisas da gente que não tem como falar pra um psicólogo, tem coisas que tu não quer falar pra um homem, né, tu quer falar pra uma mulher, dae pra nós é ruim (VALQUÍRIA,informação verbal, 2017).

Pode-se analisar de maneira empática essas questões, visto que a violência envolvendo a prática abusiva dos homens para com as mulheres em situação de rua é evidente nas vivências relatadas por elas, o que faz com que as entrevistadas tenham maior identificação com uma profissional do mesmo gênero. Outro levantamento refere-se ao atendimento médico ginecológico com agendamentos urgentes, em razão da vulnerabilidade às doenças transmissíveis. Valquíria ainda ressalta:

Uma psicóloga e uma ginecologista só pra nós, porque a gente tá muito frequente a essas doenças né, a gente que é mulher pega mais doenças. Que nem umas colegas nossas esperaram tanto que ficaram mal no hospital, e uma faleceu... Até tem, mas demora muito (VALQUÍRIA, informação verbal, 2017).

Nesses relatos, pode-se observar que as violações de direitos dessas mulheres são fatos concretos, que se comprovam no modo como sofrem severamente as condições sociais determinadas e impostas, seja no espaço da rua, manifestado pelas inter-relações, seja pelas instituições que as colocam no lugar de 'invisíveis' e negligenciadas diante de suas necessidades próprias (André Luiz Freitas DIAS et al., 2015).

O atendimento para as mulheres em situação de rua percorre a historicidade do próprio ser humano acolhido, pela negação de direitos em toda ou em boa parte da vida. É fundamental respeitar sua subjetividade, singularidade, sofrimento, frustrações e desejos, principalmente das mulheres, que aparentam sofrer ainda mais desumanidade. É imprescindível compreender que as situações que levam as mulheres a ingressarem nas ruas são segmento de um construto social opressivo e cruel, denunciando a incompetência do Estado e a omissão de apoio da sociedade. Assim, a psicologia que se manifesta a ser social precisa entender as diferenças, estando ciente dos sofrimentos ético-políticos que essas mulheres se acostumaram a viver no cotidiano, contribuindo para uma sociedade mais justa e prudente, na qual o bem-estar psíquico e a ética profissional sejam tão consideráveis quanto a equiparação social das mulheres e o progresso da nação (CONSELHO REGIONAL DE PSICOLOGIA 2a REGIÃO, 2015).

Ainda sobre as políticas de saúde, identifica-se a presença de doenças ocasionadas pelo consumo e abuso de drogas (crack e cocaína), sendo que os serviços que poderiam contribuir de maneira eficaz na sua recuperação não estão ao alcance. Cabe destacar que os serviços destinados a essa demanda, como, por exemplo, Consultório de Rua e CAPS, não estão disponíveis em todos os municípios e nem sempre são de fácil acesso. Além disso, há dificuldade até mesmo na realização dos documentos, em razão da debilidade provocada pela doença, no acesso à distribuição de medicamentos, que são vendidos, e no uso inadequado devido à dificuldade na autonomia do tratamento. Diana (informação verbal, 2017) relata em sua fala: Eu sei que tem gente que não tem documento, gente que ganha remédio, vendem os remédios quando ganham, coisa que eu preciso e não tenho, isso é uma coisa errada.

Segundo Fábio Amado (2017), no Brasil, é exigida a documentação pessoal para acessar os serviços básicos de educação, saúde, alimentação e o mercado de trabalho. Conceder às pessoas em situação de rua serviços de expedição de documentação como certidão de nascimento, Cadastro de Pessoas Físicas (CPF-MF), identidade, carteira de trabalho, entre outros, é essencial e imensamente ineficaz e dispendioso. A conservação desses documentos para quem vive na rua é precária devido às condições em que se encontram, pois a escassez de abrigo, furtos recorrentes, ações policiais e de 'ordem pública', com forçadas remoções e contato físico brusco, produzem repetidas perdas, fazendo-se necessário emitir novos documentos constantemente.

Os Centros de Atenção Psicossociais são pouco frequentados pelas entrevistadas, tendo em vista que a maioria das pessoas em situação de rua deveria fazer uso da medicação, seja por doenças mentais ou dependência química, tendo como comorbidade questões de saúde mental. Segundo os relatos, muitas não querem aderir ao tratamento devido aos efeitos do remédio, que as deixa mais vulneráveis à violência na rua. Assim, pode-se pensar de que forma estão sendo realizados os vínculos com essas mulheres e também sobre quais estratégias estão sendo utilizadas para que ocorram a adesão e a continuidade do tratamento. 
Segundo lacã Macerata, José Guilherme Neves Soares e Julia Florêncio Carvalho Ramos (2014), a população em situação de rua consiste em um dos grupos sociais que refletem uma minoria no que condiz ao acesso nos serviços de saúde. Entretanto, esse contexto vem se modificando com a implantação das equipes de Consultório na Rua (eCR), que visam atender de maneira integral as demandas de saúde e ampliar a acessibilidade quanto aos cuidados, executando acolhimentos no território ou no serviço de saúde. Diante do exposto, destaca-se que, no decorrer dessa pesquisa, o Consultório na Rua não foi citado pelas mulheres entrevistadas, uma vez que ainda está em processo de implantação na cidade de Novo Hamburgo.

O Consultório de Rua compreende uma proposta de cuidado que amplia a qualidade e o acesso da atenção à população que vivencia situação de rua. Age em parceria com as unidades básicas de saúde e os CAPS em busca de alternativas diante das crescentes e complexas demandas existentes no cotidiano da rua, ao garantir não apenas assistência à saúde, mas também assegurar os direitos como cidadão (Janaína Alves da Silveira HALLAIS; Nelson Filice de BARROS, 2015).

Outro posicionamento levantado pelas mulheres relaciona-se ao Serviço especializado em Abordagem Social. Segundo uma entrevistada, muitos moradores não conseguem acessar o serviço por desconhecimento e, por isso, mais profissionais deveriam realizar a busca na rua, para assim atingir maior parte da população nesta situação. Sobre este tema levantado pelas entrevistadas, cabe salientar que, segundo estudo divulgado pela Confederação Nacional de Municípios (CNM, 2017), são determinantes as reduções no orçamento da Assistência Social. A entidade salienta que a ação prejudica o futuro do Sistema Único de Assistência Social (SUAS). Desse modo, o Conselho Nacional de Assistência Social (2017) manifestou nota de repúdio aos cortes da proposta orçamentária da assistência social em 2018:

\begin{abstract}
A Assistência Social representa cerca de 13,9 milhões de famílias beneficiadas do Programa Bolsa Família, quase 14 mil entidades de Assistência Social no Brasil, 5.570 municípios que ofertam serviços diretamente e mais de 600 mil trabalhadores no Sistema Único de Assistência Social SUAS e não podemos aceitar a escolha do Governo Federal que tem por opção a retirada de Direitos Sociais e que toda esta parcela da população Brasileira seja totalmente desconsiderada no panorama Nacional com as necessidades básicas avaliadas como descartáveis e que fiquem à mercê dos interesses econômicos de poucos (CONSELHO NACIONAL DE ASSISTÊNCIA SOCIAL, 2017, p. 1).
\end{abstract}

Nessa crise, pode-se refletir sobre a precariedade e falta de profissionais para atender às demandas, visto que serão mais de 3 bilhões de profissionais retirados dos Serviços que atendem diretamente a população. Compete esclarecer o impacto da falta desses recursos para os brasileiros: nos serviços de acolhimento ofertados nos municípios, que cessarão de receber recursos em equipamentos estatais e da sociedade civil para oferta de abrigos, serão atingidos cerca de "30 mil crianças e adolescentes, 36 mil idosos, 20 mil adultos e famílias que se encontram em situação de rua ou desabrigo por abandono" (CONSELHO NACIONAL DE ASSISTÊNCIA SOCIAL, 2017, p. 3).

Quanto ao atendimento nos albergues, uma das principais críticas está relacionada ao número limitado de vagas. As entrevistadas relatam que o número é muito reduzido e deveria haver mais vagas para os moradores de rua, principalmente no inverno rigoroso, quando ficam mais vulneráveis às doenças respiratórias, por exemplo. Outra situação abordada são as distribuições de vagas por gênero e orientação sexual. Uma das entrevistadas diz: As transexuais têm quartos separados das mulheres então, por exemplo, preencheu seis trans, nenhuma mais entra (FÊNNIX, informação verbal, 2017).

A entrevistada explica que há muito preconceito nos albergues e, por isso, os quartos para pessoas transexuais são separados. Outro aspecto importante citado envolve o atendimento dos profissionais e o desvio do repasse de verbas. De acordo com uma das moradoras:

[...] eles deveriam dar mais coisas, porque se um albergue ganha 500 mil reais, o outro ganha 600 mil, o outro ganha 800 mil, porque a população da rua vai tá comendo arroz duro, vai tá comendo uma lavagem, vai comer um feijão aguado, como acontece isso no albergue municipal (CORA, informação verbal, 2017).

Segundo Rosimeire Barboza da Silva Correia e Alderon Pereira Costa (2014), constatou-se, em várias regiões do Brasil, a massificação de respostas emergenciais transformadas em políticas públicas definitivas, como no caso dos albergues de grandes dimensões e barracos 'para a convivência'. Mesmo em notória oposição com as diretrizes nacionais de reordenamento, esses espaços permanecem recebendo recursos sem que sejam realizadas auditorias ou fiscalizações em relação às verbas e ao seu direcionamento, ou, ainda, quanto à qualidade dos serviços oferecidos.

A rigidez das regras é um dos motivos da aversão que algumas pessoas em situação de rua têm dos albergues, pois quando chegam ao local devem deixar seus pertences em outro setor. 
Uma das moradoras compara os albergues de antigamente com os atuais, e diz que ocorreram mudanças bruscas: [...] Aqui, é morto, é uma coisa que tu só chega, toma banho e tem que dormir, a pessoa se sente mal, sabe, porque às vezes tu quer sair pro pátio... (DIANA, informação verbal, 2017). Além disso, segundo outra participante:

Os albergues como eu te falei, em Porto Alegre eu só gosto do Felipe Dill, nem o Dias da Cruz eu não gosto, porque o Dias da Cruz é que nem tipo um presídio desses de segurança máxima, eu chego lá e não posso levar minha bolsa junto comigo, eu tenho que deixar no outro setor que arrisca a pessoa a passar e levar, as coisas de importância, né, eu não posso ficar com documento comigo eu tenho que deixar lá num armário, ae eu já não vou, não podendo ficar com as minhas coisas, que tudo que eu tenho tá aqui, sem esses meus documentos eu não sou nada... (CIGANA, informação verbal, 2017).

Segundo Lancellotti (apud Débora MELO, 2016, não paginado), a lógica dos abrigos desenvolve o mesmo método das penitenciárias, com excessiva vigília: "Essas estruturas acabam reproduzindo o sistema penitenciário, principalmente no caso de estruturas muito grandes. Isso não traz autonomia, não personaliza o atendimento e não leva em conta as necessidades das pessoas".

Em relação às melhorias no atendimento, as mulheres entrevistadas citam a necessidade de melhorar o relacionamento dos profissionais com as pessoas em situação de rua, apontando a essencialidade de mais empatia e acolhimento:

[...] tratar as pessoas iguais, assim umas com as outras, não diferente uns dos outros, não ficar te olhando, tratar as pessoas um pouquinho melhor. Bah, Deus o livre, a gente é ser humano como qualquer um, eu não tenho diferença tu de mim, a única coisa é de repente tu vai tá uma mulher mais bonita, não tá no crack, não tá acabada, mas nós somos ser humanos filhos de Deus (DIANA, informação verbal, 2017).

[...] eu acho que muitas vezes, assistente social, monitor de albergue... Acho que as pessoas deveriam trabalhar com amor, entendeu? Por querer realmente ajudar o próximo, pra olhar para o outro, entendeu? Olhar para o outro e não simplesmente por um salário (FÊNIX, informação verbal, 2017).

Além disso, as entrevistadas ressaltam que, muitas vezes, os outros usuários são mais prestativos em ajudar do que os próprios profissionais. De acordo com o relatório da Organização Mundial de Saúde (OMS, 2009), a saúde de diversas mulheres está sendo afetada pela maneira como são tratadas e o status que a sociedade lhes confere. O relatório destaca o fato de que, nos locais onde ocorre maior discriminação, também acontece menor assistência, prejudicando as situações de saúde. Essas questões são reflexo do contexto social em que essas mulheres vivem e das demandas que elas carregam consigo. Por não serem assistidas como deveriam, um grande impacto é gerado na vida dessas mulheres, sobretudo no seu estado de saúde psicossocial.

Segundo Bruna de Freitas Cardoso (2009), pensar em uma política social para elas não consiste somente em construir abrigos/albergues, mas sim locais que produzam a oportunidade de ser mulher. Conviver diariamente com o machismo, a submissão e o preconceito por morarem na rua acaba por subjugar as identidades pessoal e feminina destas pessoas. Para que esse objetivo se cumpra, é necessário garantir os direitos básicos de um ser social, como cuidados médicos, higiene, beleza e, mais significativo ainda, possibilitar um convívio familiar, de forma a reconstruir os vínculos e aproximar os filhos (para aquelas que são mães). Além disso, é necessário investigar a causa que levou essas mulheres a saírem de casa e não quererem retornar - caso exista essa possibilidade.

As pessoas que vivenciam situação de rua também são vítimas de preconceito quando procuram o serviço de saúde, pois se deparam com o despreparo e a inabilidade dos profissionais de saúde para a realização da escuta qualificada e do acolhimento de suas necessidades e demandas. A isso somam-se as ações higienistas que ocorrem nos espaços públicos e que desconsideram a dignidade da vida e os direitos humanos dessas pessoas (Clara Maria Conde ANTUNES; ROSA; BRÊTAS, 2016). Dentre as principais ações higienistas vivenciadas pelas pessoas em situação de rua estão as remoções dos espaços públicos e a proibição de circulação em determinados ambientes como praças, shoppings e outros locais de convivência social.

\section{Consideraçōes finais}

O presente estudo buscou analisar as vivências de mulheres em situação de rua da região do Vale do Sinos, no Rio Grande do Sul, resgatando suas memórias, cotidiano e acesso às políticas públicas. Por meio da análise dos dados coletados, identificou-se que as as experiências de vida estão embasadas nos vínculos que se estabelecem com outros indivíduos em situação de rua, com os trabalhadores dos serviços que frequentam, além dos vínculos familiares que ainda se mantêm. Outro aspecto observado é a vulnerabilidade e o sofrimento social vivenciados pelas participantes da pesquisa e os seus desdobramentos na saúde. 
Quanto às políticas públicas, os serviços acessados pelas mulheres são Centros de Referência Especializados para População em Situação de Rua (Centro POP), abrigos, albergues, Centros de Atenção Psicossocial (CAPS), Centro de Referência de Assistência Social (CRAS), serviços filantrópicos e comunidades terapêuticas. Apesar da centralidade destes serviços na garantia dos direitos humanos, destaca-se a necessidade de escuta e envolvimento das mulheres em situação de rua tanto na concepção como no funcionamento das políticas públicas. Afinal, como afirma Cardoso (2009), pensar em uma política social para as mullheres não é somente construir abrigos ou albergues, mas sim locais que produzam a oportunidade de ser mulher. Para este objetivo, é necessário oferecer direitos básicos, tais como: cuidados médicos, higiene, beleza e convívio familiar.

Assim como Ana Paula Motta Costa (2005), entende-se que, no Brasil, é muito recente a atenção do poder público com a população em situação de rua. O descaso do Estado com essa população retrata a impugnação com que a sociedade e a concepção pública procedem à temática, ora com indulgência, atenção e até assistencialismo, ora com rejeição, indiferença e preconceito. Dessa forma, sugere-se um olhar diferenciado no atendimento para esse público, construindo ações que estimulem a participação da população em situação de rua na elaboração de políticas públicas e no funcionamento dos serviços, por meio de assembleias, consultas públicas e criação de comitês municipais. Além disso, poderiam ser pensadas estratégias para fomentar a vinculação entre os serviços e a população em situação de rua, de modo que a construção de vínculos fosse efetiva e estimulasse a adesão às diferentes modalidades de atendimentos oferecidas. Finalmente, cabe destacar que o trabalho no campo da prevenção também se faz importante, construindo alternativas que precedem a entrada das mulheres na rua. Estratégias voltadas para a saúde e assistência na atenção básica, políticas de inserção do mercado de trabalho e de inclusão na educação são alguns exemplos.

\section{Referências}

ADORNO, Rubens de Camargo Ferreira; ALVARENGA, Augusta Thereza; VASCONCELLOS, Maria da Penha. "Políticas públicas, resistências à institucionalização: populações de rua e saúde pública". In: ENCONTRO ANUAL DA ASSOCIAÇÃO NACIONAL DE PÓS-GRADUAÇÃO E PESQUISA EM CIÊNCIAS SOCIAIS (ANPOCS), 28, 2004, Caxambu. Anais... Caxambu: ANPOCS, 2004.

AGUIAR, Maria Magalhães; IRIART, Jorge Alberto Bernstein. "Significados e práticas de saúde e doença entre a população em situação de rua em Salvador, Bahia, Brasil". Cadernos de Saúde Pública, Rio de Janeiro, v. 28, n. 1, p. 115-124, 2012. Disponível em http://www.scielo.br/ scielo.php?script=sci arttext\&pid =S0102-311X2012000100012\&lng=en\&nrm=iso. Acesso em 16/08/2017.

AMADO, Fábio. "Visão do parceiro - NUDEDH - Núcleo de Defesa dos Direitos Humanos da defensoria pública do estado do Rio de Janeiro. População em situação de rua: da indiferença a políticas de inclusão". Cadernos FGV DIREITO R/O, Rio de Janeiro, v. 9, p. 17-19, 2017. Disponível em http://bibliotecadigital. fgv. br/dspace/bitstream/handle/10438/19931/Cadernos\%20FGV\%20Direito \%20Rio\%20-\%20S\%E9rie\%20Cl\%EDnicas\%20-\%20Volume\%209.pdf?sequence=6. Acesso em 06/05/2018.

ANDRADE, Luana Padilha; COSTA, Samira Lima da; MARQUETTI, Fernanda Cristina. "A rua tem um ímã, acho que é a liberdade: potência, sofrimento e estratégias de vida entre moradores de rua na cidade de Santos, no litoral do Estado de São Paulo". Saúde e Sociedade, São Paulo, v. 23, n. 4, p. 1248-1261, 2014. Disponível em http://www.scielo.br/scielo.php?script=sci arttext\&pid=S0104$12902014000401248 \& \mathrm{lng}=$ en\&nrm =iso. Acesso em 03/06/2018.

ANTUNES, Clara Maria Conde; ROSA, Anderson Silva; BRÊTAS, Ana Cristina Passarella. "From the stigmatizing disease to resignification of living on the streets". Revista Eletrônica de Enfermagem, v. 18, p. 1-9, 2016. Disponível em http://fi-admin.bvsalud.org/document/view/yx9jn. Acesso em $03 / 06 / 2018$.

BARDIN, Laurence. Análise de Conteúdo. Lisboa: Edições 70, 2009.

BRASIL. Ministério do Desenvolvimento Social e Combate à Fome. Pesquisa Nacional sobre População em Situação de Rua. Brasília: MDS, 2008.

BRASIL. Secretaria de Atenção à Saúde. Secretaria de Gestão Estratégica e Participativa. Nota Técnica Conjunta n.001: SAS e SGEP. Brasília: SAS, 2015. Disponível em http://portalarquivos.saude. gov.br/images/pdf/2015/outubro/08/Nota-t--cnica--diretrizes-e-fluxograma-mulher-sit-rua. pdf. Acesso em 10/09/2017. 
BRÊTAS, Ana Cristina Passarella; ROSA, Anderson Silva; CAVICCHIOLI, Maria Gabriela Secco. "Cuidado de enfermagem ao adulto em situação de rua". In: BRÊTAS, Ana Cristina Passarella; GAMBA, Mônica Antar. Enfermagem e saúde do adulto. Barueri: Manole, 2006. p. 145-153.

BRIOSCHI, Lucila Reis; TRIGO, Maria Helena B. "Relatos de vida em ciências sociais: considerações metodológicas". Ciência e Cultura, Campinas, v. 30, n. 7, p. 631-637, 1987. Disponível em http://www. scielo. br/scielo.php?script=sci nlinks\&ref=0001 18\&pid = $00034-7167200500020000500015 \& \mathrm{lng}=$ pt. Acesso em 12/09/2017.

CARDOSO, Bruna de Freitas. "Mulher em situação de rua: merece um olhar especial". WebArtigos, 2009. Disponível em http://www.webartigos.com/artigos/mulher-em-situacao-de-rua-merece-umolhar-especial/23576. Acesso em 15/09/2017.

CARRETEIRO, Teresa Cristina. "Sofrimentos sociais em debate". Psicologia USP, São Paulo, v. 14, n. 3, p. 57-72, 2003. Disponível em http://www.revistas. usp.br/psicousp/article/view/42241/45914. Acesso em 05/06/2018.

CNM. CONFEDERAÇÃO NACIONAL DE MUNICÍPIO. Redução no orçamento da Assistência Social compromete futuro do SUAS. Brasília: CNM, 2017. Disponível em https://www.cnm.org.br/cms/ biblioteca/Corte\%200rc\%CC\%A7amento\%20do\%20Suas\%20-.pdf. Acesso em 10/09/2018.

CONSELHO NACIONAL DE ASSISTÊNCIA SOCIAL. Nota de repúdio relativa aos cortes da proposta orçamentária da assistência social 2018. Brasília: CNAS, 2017. Disponível em http://www.mds.gov. br/cnas/capacitacao-e-boas-praticas/manifestos-do-cnas/nota-do-cnas-contra-os-cortes-daproposta-orcamentaria-para-2018.pdf. Acesso em 04/05/2018.

CONSELHO REGIONAL DE PSICOLOGIA 2a REGIÃO. "Nota: a mulher em situação de rua". Ser Digital، 2015. Disponível em http://www.serdigital.com.br/gerenciador/clientes/crp/arquivos/254.pdf. Acesso em 03/06/2018.

CORREIA, Rosimeire Barboza da Silva; COSTA, Alderon Pereira. "Os limites de um discurso abstrato: políticas públicas, população em situação de rua e direitos humanos no Brasil". Hendu - Revista Latino-Americana de Direitos Humanos, v. 5, n. 1, p. 29-38, 2014. Disponível em https://periodicos. ufpa.br/index.php/hendu/article/view/1932. Acesso em 10/05/2018.

COSTA, Ana Paula Motta. "População em situação de rua: contextualização e caracterização". Revista Virtual Textos \& Contextos, Porto Alegre, n. 4, p. 1-15, 2005. Disponível em https://core.ac.uk/ download/pdf/27033248.pdf. Acesso em 03/06/2018.

COSTA, Samira Lima da. Os sentidos da comunidade: construções intergeracionais de memória coletiva na llha das Caieiras, em Vitória, ES. 2008. Tese (Doutorado) - Programa de Pós-Graduação em Psicossociologia de Comunidades e Ecologia Social, Instituto de Psicologia, Universidade Federal do Rio de Janeiro, Rio de Janeiro, RJ, Brasil.

D'ERCOLE, Ann; STRUENING, Elmer. "Victimization among homeless women: implications for service delivery". Journal of Community Psychology, v. 18, n. 1, p. 141-152, 1990. Disponível em http:/l onlinelibrary.wiley.com/doi/10,1002/1520-6629(199004)18:2\%3C141::AID-JCOP2290180206\%3E3. 0.c0:2-O/abstract. Acesso em 12/09/2017.

DIAS, André Luiz Freitas et al. "Mulheres em situação de rua: trajetórias de invisibilidade e exclusão na construção de identidades". In: SEMINÁRIO ENLAÇANDO SEXUALIDADES, IV, 2015, Salvador, UNEB. Anais... Salvador: UNEB, 2015.

ESMERALDO FILHO, Carlos Eduardo. Saúde mental e (ex)-moradores de rua: um estudo a partir do valor pessoal e do poder pessoal. 2006. Trabalho de Conclusão de Curso (Graduação) Universidade Federal do Ceará, Fortaleza, CE, Brasil. (Disciplina no Programa de Graduação em Psicologia)

HALLAIS, Janaína Alves da Silveira; BARROS, Nelson Filice de. "Consultório na rua: visibilidades, invisibilidades e hipervisibilidade". Cadernos de Saúde Pública, Rio de Janeiro, v. 31, n. 7, p. 1497 1504, 2015. Disponível em http://www.scielo.br/scielo.php?script=sci arttext\&pid=S0102-31 1X2015 $000701497 \& \operatorname{lng}=$ en\&nrm =iso. Acesso em 06/05/2018.

HUMAN RIGHTS COUNCIL. Report of the Special Rapporteur on adequate housing as a component of the right to an adequate standard of living, and on the right to non-discrimination in this context. Nova York: Human Rights Council, 2015. Disponível em http://www.ohchr.org/Documents/lssues/ Housing/A HRC 3154 Unofficial translation Portuguese.pdf. Acesso em 12/09/2017. 
MACERATA, lacã; SOARES, José Guilherme Neves; RAMOS, Julia Florêncio Carvalho. "Apoio como cuidado de territórios existenciais: Atenção Básica e a rua". Interface, Botucatu, n. 1, v. 18, p. 919-930, 2014. Disponível em http://www.scielo.br/scielo.php?script=sci arttext\&pid=S141432832014000500919\&lng=en\&nrm=iso. Acesso em 07/05/2018.

MARCHI, Joisy Aparecida; CARREIRA Lígia; SALCl, Maria Aparecida. "Uma casa sem teto: influência da família na vida das pessoas em situação de rua". Ciência, Cuidado e Saúde, Maringá, v. 12, n. 4, p. 640-647, 2013. Disponível em http://www.periodicos.uem.br/ojs/index.php/CiencCuidSaudel article/view/22554. Acesso em 02/04/2018.

MELO, Débora. "O que afasta a população de rua dos albergues?". Carta Capital, 2016. Disponível em https://www. cartacapital.com.br/sociedade/o-que-afasta-a-populacao-de-rua-dos-allbergues. Acesso em 05/03/2018.

NATALINO, Marco Antonio Carvalho. Texto para discussão: estimativa da população em situação de rua no Brasil. Brasília: IPEA, 2016. Disponível em http://www.ipea.gov.br/portal/images/stories/ PDFs/TDs/26102016td 2246.pdf. Acesso em 21/08/2017.

OMS. ORGANIZAÇÃO MUNDIAL DE SAÚDE. Mulheres e saúde: evidências de hoje, agenda de amanhã. Brasília: OMS, 2009. Disponível em http://www.who.int/ageing/mulheres saude.pdf. Acesso em 06/05/2018.

PEREIRA, Viviane de Souza. População de rua em Juiz de Fora: uma reflexão a partir da questão social. 2007. Dissertação (Mestrado) - Pós-Graduação em Serviço Social, Universidade Federal de Juiz de Fora, Minas Gerais, MG, Brasil. Disponível em https://repositorio.uffif.br/ispui/bitstream/ ufif/2478/1/vivianesouzapereira.pdf. Acesso em 17/09/2017.

PORTO ALEGRE. Cadastro e mundo da população em situação de rua de Porto Alegre/RS. Porto Alegre: FASC, 2016. Disponível em http://www2.portoalegre.rs.gov.br/fasc/default.php?p $\underline{\text { secao }=120}$. Acesso em 10/09/2017.

PRODANOV, Cleber Cristiano; FREITAS, Ernani Cesar de. Metodologia do trabalho científico: métodos e técnicas da pesquisa e do trabalho acadêmico. 2. ed. Novo Hamburgo: Feevale, 2013.

ROSA, Anderson da Silva. Mulheres em situação de rua na cidade de São Paulo: um olhar sobre trajetórias de vida. 2012. Tese (Doutorado) - Pós-Graduação em Enfermagem, Universidade Federal de São Paulo, São Paulo, SP, Brasil.

ROSA, Anderson da Silva; CAVICCHIOLI, Maria Gabriela Secco; BRÊTAS, Ana Cristina Passarella. "O processo saúde-doença-cuidado e a população em situação de rua". Revista Latino-Americana de Enfermagem, Ribeirão Preto, v. 13, n. 4, p. 576-582, 2005. Disponível em http://www.scielo.br/scielo. php?script=sci_arttext\&pid=S0104-1 169200500040001 7\&lng=en\&nrm=iso. Acesso em 17/09/2017.

SANTANA, Carmen Lúcia Albuquerque de; ROSA Anderson da Silva (Orgs.). Saúde mental das pessoas em situação de rua: conceitos e práticas para profissionais da assistência social. São Paulo: Epidaurus Medicina e Arte, 2016.

SCHUCH, Patrice et al. "População em situação de rua: conceitos e perspectivas fundamentais". In: GEHLEN, Ivaldo; SILVA, Simone Ritta; BORBA, Marta (Orgs.). Diversidade e Proteção Social: estudos quanti-qualitativos das populações de Porto Alegre - afro-brasileiros; crianças, adolescentes e adultos em situação de rua; coletivos indígenas; remanescentes de quilombos. Porto Alegre: Century, 2008. p. 13-30.

SOTERO, Marília. "Vulnerabilidade e vulneração: população de rua, uma questão de ética". Revista Bioética, Brasília, v. 19, n. 3, p. 799-81 7, 2011 . Disponível em http://revistabioetica.cfm.org.br/index. php/revista_bioetica/article/view/677/709. Acesso em 03/05/2018.

SPINDOLA, Thelma; SANTOS, Rosângela da Silva. "Trabalhando com a história de vida: percalços de uma pesquisa(dora?)". Revista Escola de Enfermagem da USP, São Paulo, v. 37, n. 2, p. 119-126, 2003. Disponível em http://www.ee.usp.br/reeusp/upload/pdf/207.pdf. Acesso em 06/09/2017.

TIENE, Izalene. Mulher moradora na rua: entre vivências e políticas sociais. Campinas: Alínea, 2004.

TIRADENTES, Luciana Rossani; FERNANDES, Rosa Aurea Quintella. "Diagnósticos de enfermagem identificados em mulheres em situação de rua". Online Brazilian Journal of Nursing, Niterói, v. 7, n. 1, 2008. Disponível em http://www.objnursing.uff.br/index.php/nursing/article/ view/i. 1676-4285,2008,1356. Acesso em 10/09/2017. 
WENZEL, Suzanne L.; LEAKE, Barbara D.; GELBERG, Lilian. "Health of homeless women with recent experience of rape". Journal of General Internal Medicine, Maryland, v. 15, n. 1, p. 265-268, 2000. Disponível em https://www.ncbi.nlm.nih.gov/pmc/articles/PMC1495443/. Acesso em 04/09/201 7.

Scarleth Nardes (scarleth kaquis@hotmail.com) é graduada em Psicologia pela Universidade Feevale e psicóloga clínica do consultório.

Carmem Regina Giongo (ca.aiesec@gmail.com) é psicóloga, mestre em Psicologia, doutora e pós-doutora em Psicologia Social e Institucional pela UFRGS. É pesquisadora do Núcleo de Estudos e Pesquisa em Saúde e Trabalho da UFRGS, docente do curso de Psicologia da Feevale e pós-doutoranda na Université Paris Nanterre. Atua no Comitê de Acompanhamento e Monitoramento da Política Municipal para a População em Situação de Rua de NH.

\section{COMO CITAR ESSE ARTICO DE ACORDO COM AS NORMAS DA REVISTA}

NARDES, Scarleth; GIONGO, Carmem Regina. "Mulheres em situação de rua: memórias, cotidiano e acesso às políticas públicas". Revista Estudos Feministas, Florianópolis, v. 29, n. 1, e6601 1, 2021.

\section{CONTRIBUIÇĀO DE AUTORIA}

Scarleth Nardes: concepção, coleta de dados e análise de dados, elaboração do manuscrito, redação, discussão de resultados.

Carmem Regina Giongo: concepção, análise de dados, elaboração do manuscrito, redação, discussão de resultados

\section{FINANCIAMENTO}

Não se aplica.

\section{CONSENTIMENTO DE USO DE IMAGEM}

Não se aplica.

\section{APROVAÇĀO DE COMITÊ DE ÉTICA EM PESQUISA}

Número do parecer: 3.099.498.

\section{CONFLITO DE INTERESSES}

Não se aplica.

\section{LICENÇA DE USO}

Este artigo está licenciado sob a Licença Creative Commons CC-BY 4.0 International. Com essa licença você pode compartilhar, adaptar, criar para qualquer fim, desde que atribua a autoria da obra.

\section{HISTÓRICO}

Recebido em 01/07/2019

Reapresentado em 27/02/2020

Reapresentado em 22/04/2020

Aprovado em 15/06/2020

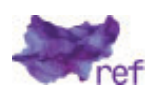

